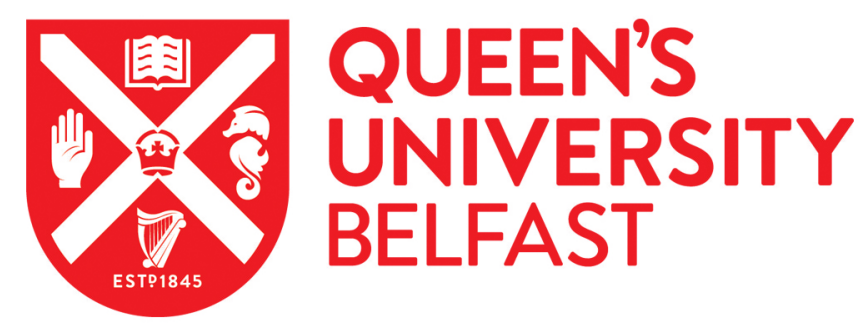

\title{
Engaging a Battle on Two Fronts: Dual Role of Polyphosphates as Potent Inhibitors of Struvite Nucleation and Crystal Growth
}

Kim, D., Moore, J., McCoy, C., Irwin, N., \& Rimer, J. (2020). Engaging a Battle on Two Fronts: Dual Role of Polyphosphates as Potent Inhibitors of Struvite Nucleation and Crystal Growth. Chemistry of Materials, 32(19), 8672. https://doi.org/10.1021/acs.chemmater.0c03180

Published in:

Chemistry of Materials

Document Version:

Peer reviewed version

Queen's University Belfast - Research Portal:

Link to publication record in Queen's University Belfast Research Portal

Publisher rights

Copyright 2020 ACS. This work is made available online in accordance with the publisher's policies. Please refer to any applicable terms of use of the publisher.

\section{General rights}

Copyright for the publications made accessible via the Queen's University Belfast Research Portal is retained by the author(s) and / or other copyright owners and it is a condition of accessing these publications that users recognise and abide by the legal requirements associated with these rights.

Take down policy

The Research Portal is Queen's institutional repository that provides access to Queen's research output. Every effort has been made to ensure that content in the Research Portal does not infringe any person's rights, or applicable UK laws. If you discover content in the Research Portal that you believe breaches copyright or violates any law, please contact openaccess@qub.ac.uk. 


\title{
Engaging a Battle on Two Fronts: Dual Role of Polyphos- phates as Potent Inhibitors of Struvite Nucleation and Crystal Growth
}

\author{
Doyoung Kim ${ }^{1}$, Jessica Moore ${ }^{2}$, Colin P. McCoy², Nicola Jayne Irwin², and Jeffrey D. Rimer ${ }^{1, *}$ \\ ${ }^{1}$ Chemical and Biomolecular Engineering, University of Houston, Houston, TX 77204, USA \\ ${ }^{2}$ School of Pharmacy, Queen's University Belfast, Belfast, Northern Ireland, UK
}

\begin{abstract}
Polyprotic acids often serve as effective regulators of inorganic crystallization in natural, biological, and synthetic systems. These molecules or macromolecules can function as efficient modifiers that either inhibit or promote crystal growth. Few studies report potent inhibitors of crystal nucleation owing to the presumed challenges of hindering these stochastic events; however, in this study we have identified polyphosphates that operate as potent inhibitors of both nucleation and crystal growth of the natural mineral struvite $\left(\mathrm{MgNH}_{4} \mathrm{PO}_{4} \cdot 6 \mathrm{H}_{2} \mathrm{O}\right)$, which is a common component of scale in commercial and physiological processes (e.g. water purification and kidney disease). Systematic investigation of linear and cyclic polyphosphates of varying molecular weight reveal that micromolar concentrations of three modifiers, hexametaphosphate, polyphosphate type 45, and phytic acid, lead to suppressed struvite nucleation. Combined studies of struvite growth at the macroscopic level using microfluidics to track anisotropic rates of crystallization and at the molecular level using in situ atomic force microscopy (AFM) to monitor layered growth of crystal surfaces collectively reveal that these modifiers are also capable of fully suppressing crystal growth via their affinity to interact with all principal crystal facets. Time-resolved AFM images of the (101) surface at varying polyphosphate concentrations reveal a unique mode of crystal growth inhibition wherein surfaces become laden with an amorphous layer that leads to roughened interfaces and growth succession through dynamic sequences that are not commonly witnessed for other minerals. It is also observed under certain conditions that inhibitors can induce significant changes in crystal morphology, leading to exquisite leaf-like hierarchical structures. The discovery of potent inhibitors of struvite formation that operate by unparalleled dual modes of action capable of suppressing both nucleation and crystal growth has potential implications for their use in the prevention of commercial scale in water purification as well as in the treatment of kidney stones. Moreover, the fundamental mechanisms of polyphosphates identified in this study may prove to be relevant for other inorganic crystals given the ubiquitous use of inhibitors in processes spanning from biomineralization to crystal engineering.
\end{abstract}

\section{INTRODUCTION}

The formation of inorganic scale, such as struvite $\left(\mathrm{MgNH}_{4} \mathrm{PO}_{4} \cdot 6 \mathrm{H}_{2} \mathrm{O}\right)$, is often an unwanted outcome that negatively impacts the efficiency of commercial processes, such as water treatment ${ }^{1-11}$, and is implicated in pathological diseases, such as infection stones ${ }^{12,13}$. Management of patients with infection stones is challenging due to the high recurrence rates, and without appropriate treatment can result in death from sepsis. ${ }^{14}$ Scale is particularly problematic in wastewater where high levels of magnesium, ammonia, and phosphate create supersaturated media that promotes struvite crystallization. Precipitation of inorganic scale often compromises the operation and longevity of commercial equipment, while its accumulation in pipes leads to constrictions that restrict flow, leading to reduced treatment capacity and higher energy costs for the transport of water. Many efforts have been made to effectively control struvite formation to bypass the need for mechanical removal. For example, it has been shown that induced precipitation in flow by either maintaining mildly acidic conditions or using pulses of electric energy can avoid buildup on the surfaces of pipes ${ }^{15,16}$. Metal ions in solution can be removed by chelating agents, although this approach requires excessive volumes of the latter ${ }^{17,18}$. Preventative measures also include the use of chemicals that interact with the surface of scale and inhibit crystal growth. It is reported that growth modifiers, or so-called "threshold" inhibitors, can be effective at trace con- centrations (e.g. $<1 \%$ of the solute) ${ }^{19}$. While commercial inhibitors have been used to prevent struvite formation, few studies in literature have examined the mechanism by which these molecules selectively bind to crystal facets and impede surface growth.

A common functional moiety of inorganic crystal growth inhibitors is carboxylic acids ${ }^{20,2122}$; however, there have been numerous studies reporting that molecules containing phosphates can be more potent inhibitors ${ }^{23-26}$. Phosphorylated organic molecules such as phytate ${ }^{27}$, phosphoproteins (e.g. osteopontin $^{28,29}$ ), and peptides ${ }^{30-33}$ derived from proteins have been shown to effectively regulate mineralization. Phytate (or phytic acid) is a natural compound comprised of a cyclohexane backbone decorated with six phosphates. It is found in most plant foods and is a reported inhibitor of calcification ${ }^{34}$. More generally, it has been shown that polyphosphates (PolyPs) are effective inhibitors of inorganic scales ${ }^{24,35,36}$ and biominerals $^{23}$. In select cases, PolyPs can impede the transformation of amorphous precursors (e.g. amorphous calcium carbonate or amorphous calcium phosphate) to crystalline products $^{37-39}$, whereas other examples have demonstrated the ability of PolyPs to alter crystal habit (size and morphology) via their putative adsorption on discrete growth sites of crystal surfaces $^{23,38,40}$. 
Previous studies of struvite crystallization have identified a select number of compounds (i.e. pyrophosphate ${ }^{41,42}$, phosphocitrate ${ }^{43}$, and hexametaphosphate ${ }^{24}$ ) that inhibit mineral formation $^{39-42}$; however, the exact mode of action for all reported struvite growth inhibitors has remained elusive. Understanding the mechanisms of inhibitor-crystal interactions and their impact on the kinetics of crystallization is critical for developing more efficient scale inhibitors. Similar knowledge has been used to design inhibitors for a broad range of crystals. For instance, our group has previously shown that adsorption of certain inhibitors leads to the dissolution of calcium oxalate monohydrate in supersaturated media by inducing strain on the crystal lattice ${ }^{44}$.

Herein, we present a comprehensive investigation of struvite crystallization at both macroscopic and microscopic length scales in the absence and presence of various PolyP inhibitors. In situ measurements of bulk crystal growth by microfluidics were used to track changes in anisotropic growth rates, whereas time-resolved atomic force microscopy (AFM) was used to elucidate the modes of inhibition at near molecular level. Our findings reveal unique mechanisms of struvite crystal growth inhibition, including the ability of PolyPs to function as dual inhibitors of nucleation and crystal growth.

\section{RESULTS AND DISCUSSION}

Inhibitors of Struvite Crystallization. We screened a series of PolyP (macro)molecules as potential inhibitors of struvite crystallization, restricting our selection to six commercially-available compounds listed in Figure 1A. These compounds include five PolyPs containing different numbers of phosphate groups and distinct structures (linear or cyclic): pyrophosphate (PP), trimetaphosphate (TMP), triphosphate (TP), hexametaphosphate (HMP), and polyphosphate type 45 (P45). We also examined the effect of phytic acid (PA). Bulk crystallization assays were conducted using identical weight percentages of each compound (i.e. similar number of total phosphate groups) for direct comparison of efficacy.

Struvite crystallization was carried out in supersaturated solutions with a starting $\mathrm{pH}$ of 8.6 , where $\mathrm{HPO}_{4}{ }^{2-}$ is the dominant phosphate species (Figure S1). The incorporation of each phosphate into the crystal results in the release of a proton $^{10}$,

$$
\mathrm{Mg}^{2+}+\mathrm{NH}_{4}^{+}+\mathrm{HPO}_{4}^{2-}+6 \mathrm{H}_{2} \mathrm{O} \leftrightarrow \mathrm{MgNH}_{4} \mathrm{PO}_{4} \cdot 6 \mathrm{H}_{2} \mathrm{O}+\mathrm{H}^{+}
$$

The corresponding decrease in $\mathrm{pH}$ during crystallization allows for the extent of reaction to be monitored as a function of time (for more details refer to the Supporting Information, $\mathrm{SI})$. Using the final $\mathrm{pH}$ of solutions as an estimate of the thermodynamic equilibrium (i.e. relative to control samples in the absence of additives), we compared the extent of reaction for each putative inhibitor (Figure 1B) using a fixed concentration of $50 \mu \mathrm{g} \mathrm{mL}^{-1}$ PolyP. Our findings reveal three categories of growth inhibitors. The first is those having very little impact on struvite crystal growth, which are PP, TP, and TMP. All of these compounds contain three or fewer phosphates. Prywer et $a l .{ }^{45}$ reported that PP is an effective inhibitor of struvite formation; however, the concentration of PP used in their study was an order of magnitude higher than the one used in our study, which likely explains the difference in performance. When the concentration of inhibitor approaches that of the solute, it is possible to observe thermodynamic effects as a result of phosphate sequestration of free $\mathrm{Mg}^{2+}$ ions, which lowers supersaturation and reduces the rate of crystallization. For all experiments reported herein, we intentionally used much lower concentrations of PolyPs in

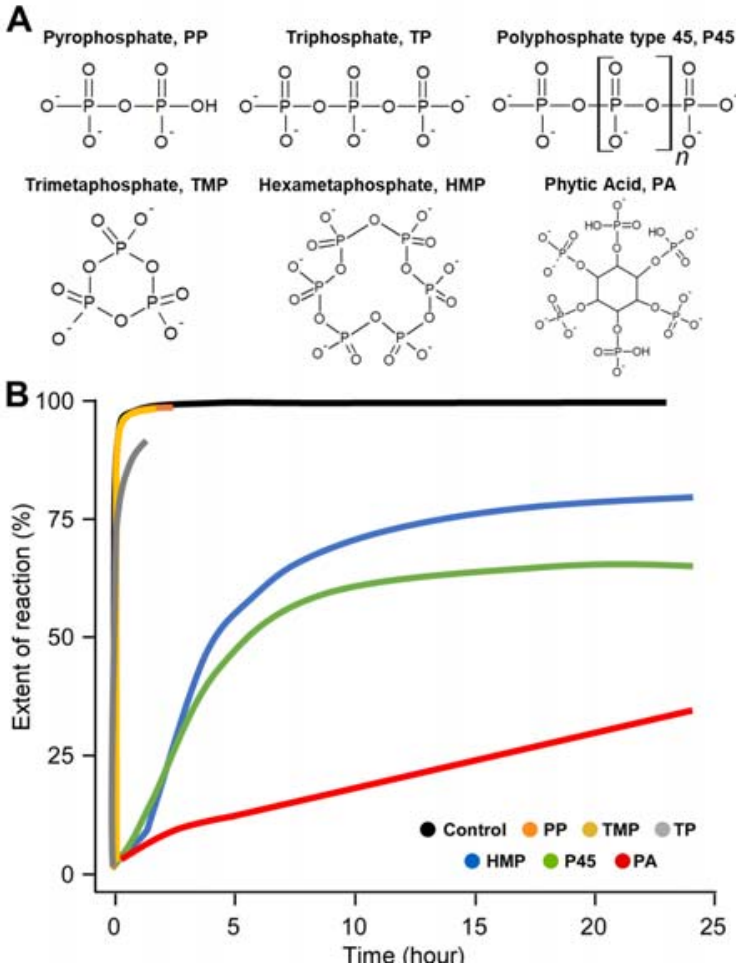

Figure 1. Screening the efficacy of polyphosphates to inhibit struvite crystallization. (A) Structures of the phosphate-based compounds tested in bulk crystallization assays. (B) Kinetic studies of struvite formation at $21 \pm 1{ }^{\circ} \mathrm{C}$ in the absence (black line) and presence of $50 \mu \mathrm{g} \mathrm{mL}^{-1}$ of additives. The extent of reaction is based on measured changes in $\mathrm{pH}$ under constant stirring for solutions prepared with an initial composition of 7 $\mathrm{mM} \mathrm{MgCl} 2 \cdot \mathrm{H}_{2} \mathrm{O}: 7 \mathrm{mM} \mathrm{NH}_{4} \mathrm{H}_{2} \mathrm{PO}_{4}: 150 \mathrm{mM} \mathrm{NaCl}$ and starting $\mathrm{pH}$ 8.6. These are representative curves from a minimum of three trials for each sample where characteristic features (e.g. induction times and rates of reaction) are reproducible.

relation to solute concentration to avoid the potential effects of ion sequestration. The second class of modifiers, which demonstrate moderate inhibition (i.e. $<40 \%$ reduction in the extent of reaction), include HMP and P45. The third class is a single outlier, PA, which is the most effective among all phosphates assayed. There is an approximate $15 \mathrm{~min}$ delay in the induction time for nucleation of solutions containing HMP and $\mathrm{P} 45$, as indicated by a stable solution $\mathrm{pH}$. The same effect was observed for PA; however, the onset of a gradual increase in the extent of reaction (Figure 1B) for PA is not seemingly associated with the nucleation and growth of struvite, but is the result of an amorphous precipitate. Evidence for the complete suppression of struvite nucleation by PA is gleaned from polarized optical micrographs indicating the lack of crystallinity (and absence of distinct morphology) of collected solids under conditions of stirring (Figure S2) and under quiescent conditions (Figure 2A and $\mathrm{B}$ ) compared to the birefringence of control crystals (Figure 2C and D). The quantity of amorphous precipitate is minute, such that attempts to extract sufficient material (even with scale up) for ex situ characterization was not possible; however, our observation of an amorphous phase is qualitatively consistent with previous studies. For example, Prywer et al. detected the formation of residual amorphous material during struvite crystallization ${ }^{46}$ and showed that its formation was promoted by (-)-epicatechin. ${ }^{47}$ 
Moreover, Hövelmann et al. ${ }^{5}$ showed that cobalt ions $\left(\mathrm{Co}^{2+}\right)$ in excess of $0.5 \mathrm{mM}$ resulted in the formation of an amorphous (Mg-)Co-phosphate precursor. The exact mechanism by which PA inhibits struvite nucleation is not well understood. It has been speculated ${ }^{2}$ that struvite formation (under certain conditions) may involve crystallization by particle attachment, or $\mathrm{CPA}^{48}$. Although it is unclear whether struvite grows by classical (monomer addition) and/or nonclassical (CPA) pathways, our findings identify phytate (PA) as a potent inhibitor of struvite formation. Most notably, it is rare to encounter molecules capable of completely suppressing crystal nucleation, even among the most effective modifiers of mineralization $^{49}$

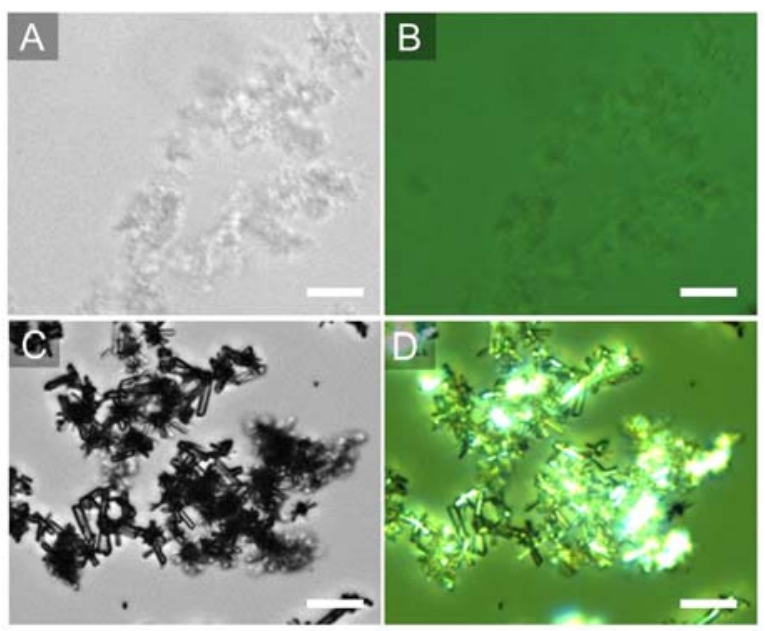

Figure 2. Optical $(A, C)$ and polarized $(B, D)$ micrographs of materials formed in the presence of $50 \mu \mathrm{g} \mathrm{mL}^{-1}$ PA (A,B) and in the absence of an inhibitor $(C, D)$ under quiescent conditions. Aliquots of samples were placed on glass slides for imaging. Polarized micrographs reveal the amorphous (B) and crystalline (D) nature of collected materials. Amorphous precipitate in growth solutions containing PA was also observed for experiments under stirring (Figure S2). Scale bars are equal to $25 \mu \mathrm{m}$.
Bulk crystallization assays in Figure 1 were conducted under constant stirring. A parallel study under quiescent conditions using identical supersaturation and inhibitor concentration $\left(50 \mu \mathrm{g} \mathrm{mL}^{-1}\right)$ was performed to assess the effect of each PolyP on struvite nucleation (Figure S3 in the SI). Crystallization in the absence of any additives resulted in layers of crystals collected at the bottom of synthesis vials (Figure S3A). Experiments performed with the three weak inhibitors identified in Figure 1 (i.e. PP, TMP, and TP) revealed similar populations of crystals, consistent with the extent of reaction measurements confirming their negligible effect on struvite nucleation (Figure S3B-D). Interestingly, the PolyPs identified as moderately effective inhibitors in Figure 1 (i.e. HMP and $\mathrm{P} 45$ ) were found to suppress nucleation under quiescent conditions. This was evident by the lack of visible precipitate at the bottom of the crystallization vials as well as optical micrographs showing only a few crystals (Figure S3E and F). Nucleation suppression was also observed for growth solutions containing PA under both quiescent (Figures 2A and S3G) and stirring (Figures 1 and S2A) conditions. One notable difference among inhibitors was the formation of amorphous precipitate, which was only observed for PA while both HMP and P45 maintained a supersaturated (metastable) solution. Collectively, these results reveal distinct differences in the effect of inhibitors under stirring and quiescent conditions. Indeed, switching from a dynamic growth environment to one that is static increases the number of potent nucleation inhibitors from one (PA) to three (HMP, P45, and PA), respectively.

Here we compare the effects of PolyPs on struvite crystal growth using a combination of electron and optical microscopy to examine time-resolved evolution of crystal size and habit. In the presence of PP and TMP, struvite crystals exhibit an elongated tabular habit (Figure S4B and C, respectively) that is indistinguishable from that of the control (Figure S4A). On the contrary, TP had a significant
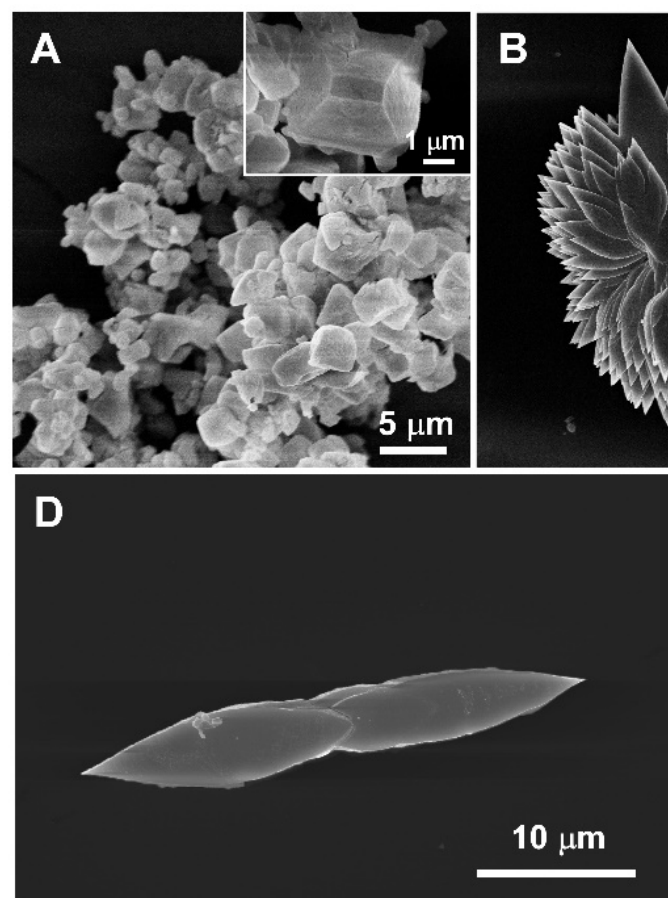

B
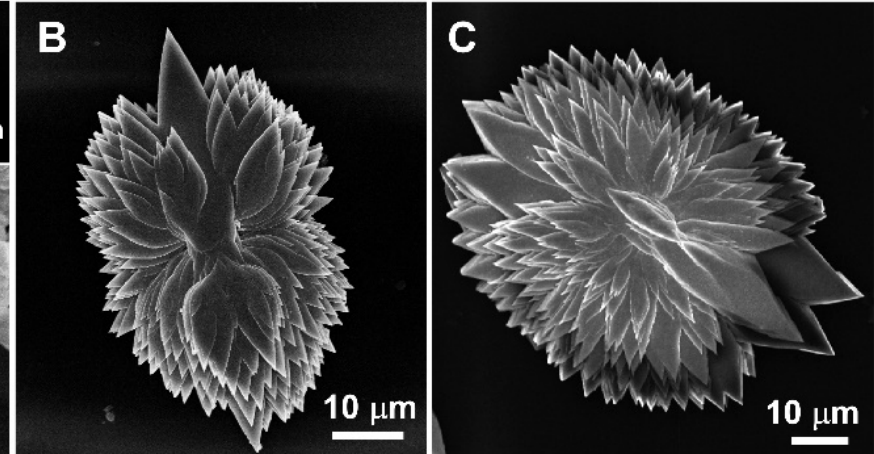

E 


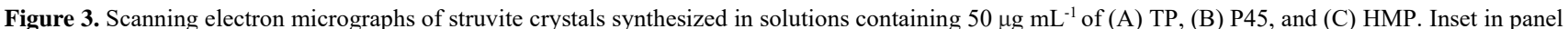
$A$ is a high magnification image of a representative crystal. (D and E) Time-elapsed SEM images of representative struvite crystals extracted from growth solutions containing HMP after (D) $4 \mathrm{~h}$ and (E) $8 \mathrm{~h}$.

effect on struvite morphology despite having only a marginal impact on the extent of reaction (compared to TMP and PP). Notably, scanning electron microscopy (SEM) images of crystals prepared with TP indicate its preferential binding to surfaces growing in the $b$ direction (i.e. the fastest growth direction of struvite), leading to a reduction in the $a / c$ and $b / c$ aspect ratios (Figure 3A). There is also a net reduction in the size of struvite crystals ( $b$ direction) from $7 \pm 4 \mu \mathrm{m}$ (control) to $2.4 \pm 0.9 \mu \mathrm{m}$ in the presence of TP. This outcome is highly uncommon for crystal growth modifiers exhibiting such weak effects on the kinetics of crystallization. It also highlights the subtle differences in the number of phosphate groups (TP has three compared to two for PP), and the altered arrangement of three phosphate groups from a linear motif for TP to a cyclic one for TMP.

Increasing the number of phosphate groups from 3 (TP) to $45(\mathrm{P} 45)$ results in a significant reduction in the number of crystals collected in the final product (Figure S3F) as well as a morphology that is quite unusual (Figure 3B). The crystals formed in the presence of $\mathrm{P} 45$ have a shape resembling a spiral leaf, and a structure that was confirmed to be struvite based on its powder X-ray diffraction pattern (Figure S5). Interestingly, the same crystal morphology was directed by HMP (Figure 3C), which was unexpected in view of the distinct differences in HMP and P45 structures (i.e. ring vs. linear chain). Time-resolved SEM images of struvite crystals grown in 50 $\mu \mathrm{g} \mathrm{mL} \mathrm{mL}^{-1}$ HMP reveal the initial formation of a "seed" with a distinctive and highly reproducible shape (Figure 3D), consistent with images of early-stage crystals extracted from solutions containing P45 (Figure S6). The evolution of these features involves sequential branching (Figure $3 \mathrm{E}$ ) and growth of individual platelets (or leaves) that encompass the initial seed

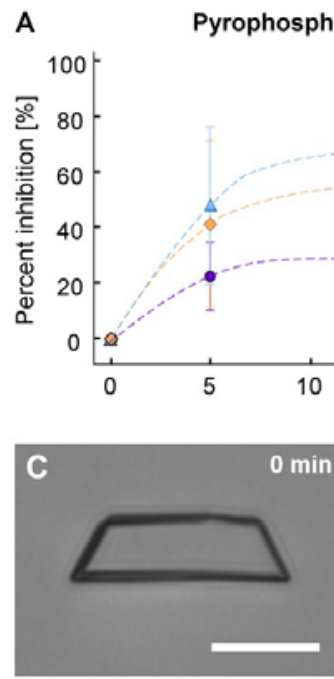

Pyrophosphate (PP)
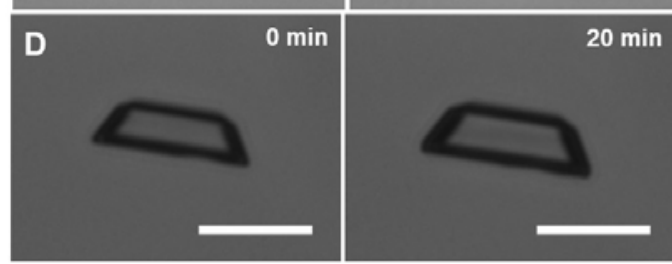

to form a symmetrical (Figure 3B and C), or sometimes asymmetrical (Figure S7), hierarchical struvite crystal. The preferential binding of HMP and P45 to facets of struvite is difficult to discern; however, it is interesting to note that seeds (Figure 3D) appear elongated in the $c$ direction, which is the opposite of naturally grown struvite that exhibits preferential growth in the $b$ direction (Figure S8).

Microfluidics Analysis of Crystal Growth Inhibition. The extent of crystallization measured in Figure 1B cannot distinguish between the effects of nucleation and crystal growth inhibition. To this end, we assessed struvite growth at a macroscopic level using a microfluidics device (Figure S9) where channels were seeded with struvite crystals to bypass nucleation and focus solely on quantifying anisotropic growth under a constant flow of supersaturated solution with or without inhibitors. Sequential images from time-resolved optical microscopy were used to assess changes in crystal dimensions in all three principal growth directions by statistically sampling multiple crystals oriented (normal to the plane of imaging) in both the $c$ - and $a$-directions. We first analyzed the dependence of struvite growth on inhibitor concentration for two mildly effective modifiers: PP and TP. The percent inhibition of struvite in the presence of PP (Figure 4A) exhibits the following trend (from highest to lowest): $\vec{b}, \vec{c}$, and $\vec{a}$. The preferential inhibition by PP in the $b$-direction is evident in timeelapsed images (Figure 4C) showing an increased $c / b$ aspect ratio. Comparison with TP reveals a more pronounced effect on struvite growth (Figure 4B) with the following trend (from highest to lowest): $\vec{b}, \vec{a}$, and $\vec{c}$. Indeed, TP almost fully suppresses growth in the $b$-direction (ca. $90 \pm 9 \%$ inhibition), which is apparent in micrographs extracted

B

Triphosphate (TP)
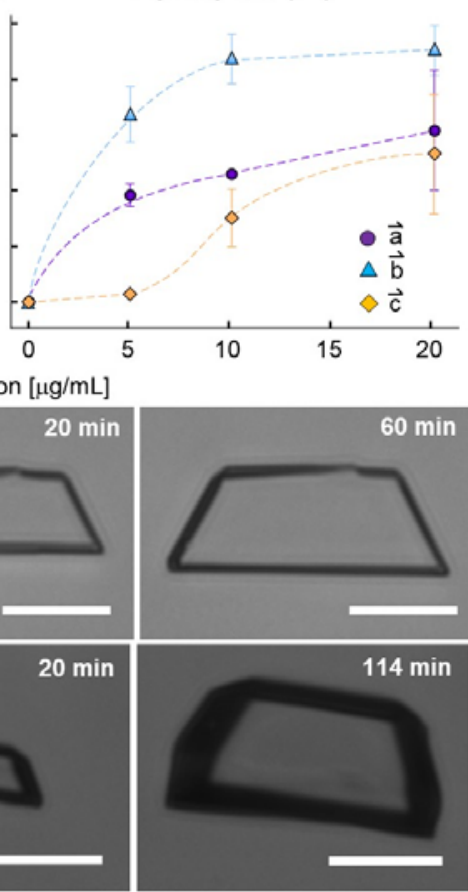

Figure 4. (A-B) Percent inhibition of struvite crystal growth along three crystallographic directions as a function of (A) PP and (B) TP concentration. Each data point represents the average measurements of 30 or more crystals in a single batch using the microfluidics platform. Error bars span two standard deviations. The growth solution consisted of $2.5 \mathrm{mM} \mathrm{MgCl}_{2} \cdot \mathrm{H}_{2} \mathrm{O}: 2.5 \mathrm{mM} \mathrm{NH}_{4} \mathrm{H}_{2} \mathrm{PO}_{4}: x \mu \mathrm{g} \mathrm{mL}{ }^{-1}$ inhibitor. Dashed lines are interpolations to guide the eye. 
All experiments were conducted at room temperature and $\mathrm{pH}$ 8.6. (C and D) Time-elapsed optical micrographs demonstrating the effects of $5 \mu \mathrm{g} \mathrm{mL}^{-1}(\mathrm{C}) \mathrm{PP}$ and (D) TP on struvite growth under solution flow $\left(24 \mathrm{~mL} \mathrm{~h}^{-1}\right)$. The scale bar for all images is equal to $20 \mu \mathrm{m}$.

from Movie S1 at periodic times (Figure 4D) showing much larger $c / b$ aspect ratio for TP compared to that with PP. These changes in struvite crystal morphology observed during microfluidics analysis of TP and PP are consistent with bulk crystallization assays under quiescent conditions (Figures 2A and S4B).

For microfluidics studies we selected a range of inhibitor concentrations $\left(1-20 \mu \mathrm{g} \mathrm{mL}^{-1}\right)$ to avoid any potential reduction in supersaturation due to inhibitor complexation of free $\mathrm{Mg}^{2+}$ ions in solution (i.e. molar ratio of inhibitor/ $\mathrm{Mg}^{2+}<$ 0.03 ). The monotonic change in percent crystal inhibition with increasing inhibitor concentration exhibits a Langmuir-like behavior, which is characteristic of most inhibitor-crystal adsorption profiles. ${ }^{21,44}$ The percent inhibition reaches a plateau at some threshold inhibitor concentration, beyond which further addition of either PP or TP has little added effect on the rate of struvite growth. Interestingly, the profile for TP in the $c$-direction exhibits a sigmoidal shape that deviates from other profiles, which seems to indicate a higher tolerance for struvite growth on these facets at low coverage of TP. In the Supporting Information we provide the time-resolved analysis of TMP, the least effective inhibitor, and show that the percent inhibition is less than $25 \%$ without any observable specificity for TMP adsorption on struvite crystals (Figure S10).

In Figure 5A we compare the maximum percent inhibition at $20 \mu \mathrm{g} \mathrm{mL}{ }^{-1}$ of PP, TP, and TMP. Similar measurements performed with HMP, P45, and PA resulted in complete suppression of crystal growth, even at much lower inhibitor concentration $\left(1 \mu \mathrm{g} \mathrm{mL}^{-1}\right)$. This is evident from Movie S2 showing a single struvite crystal in a microfluidic channel where growth is unhindered in the absence of inhibitor (Figure 5B, control) and is completely stunted in all directions for potent inhibitors (e.g. Figure 5C for PA). It is interesting to note that under conditions of flow it is possible to fully inhibit struvite growth, whereas under constant stirring (Figure 1B) growth is only partially hindered. Conversely, under both conditions the most potent inhibitor, PA, fully suppresses nucleation and crystal growth. We are not aware of examples in the literature where a crystal growth modifier functions in a dual manner with such efficacy. Hereafter, we focus exclusively on the most potent inhibitors to investigate the underlying mechanism governing their ability to fully arrest struvite growth.

In situ AFM Characterization of Surface Dynamics. It has been suggested by others that PolyPs inhibit struvite growth either by chelating free $\mathrm{Mg}^{2+}$ ions ${ }^{24,35}$ or by interacting with crystal surfaces ${ }^{42}$; however, until now PolyPs have been shown to have a moderate effect on struvite formation while their specific impact on crystal growth has been gleaned from bulk techniques limited in their ability to provide molecularlevel information regarding inhibitor-crystal interactions and their impact on surface growth. To this end, we used in situ AFM to elucidate the mechanism of inhibitory action that leads to the full suppression of crystal growth. AFM has proven to be a powerful technique for characterizing the growth of crystal surfaces in the absence and presence of inhibitors. We recently used in situ AFM to establish that struvite crystal growth follows a classical mechanism whereby new layers nucleate on crystal surfaces and advance by the incorporation of solute molecules at steps ${ }^{50}$. Indeed, a snapshot of a (101) surface during growth in supersaturated solution (Figure 6A) shows the presence of layers emanating from the bottom left (outside the frame of imaging) with heights equivalent to a single unit cell $(\mathrm{h}=0.58 \mathrm{~nm})$. After a period of growth in the presence of $0.3 \mu \mathrm{g} \mathrm{mL}^{-1} \mathrm{HMP}$, we observe a sequence of topographical changes in snapshots from Movie S3 showing an initial decrease in step density with 2-dimensional islands more visible (Figure 6B). This is then followed by a return to a higher step density, but with steps advancing from the bottom right that are comprised of corrugated edges (Figure 6C). According to classical

A
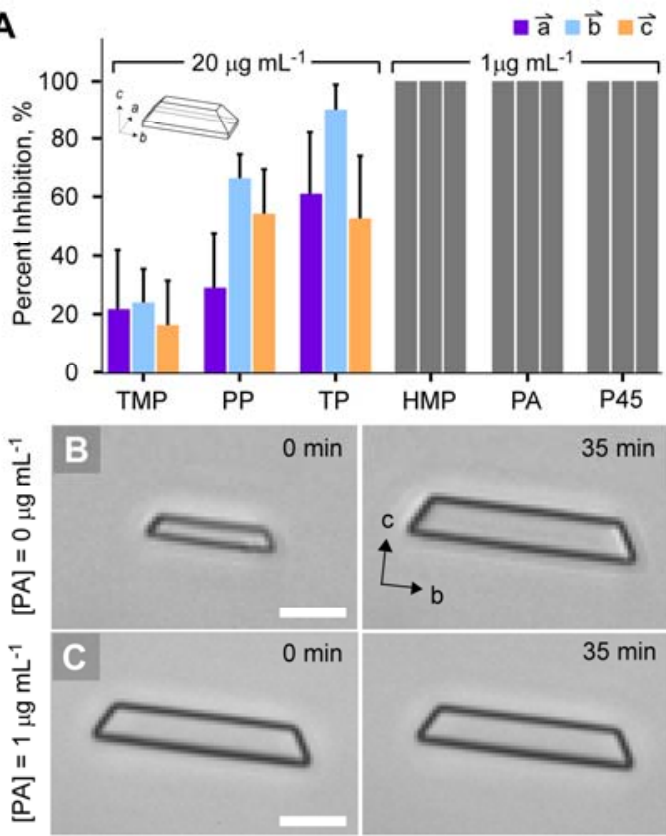

Figure 5. (A) Percent inhibition of struvite growth in the presence of phosphate inhibitors measured by microfluidics to assess differences in all three principal directions of growth: [101] (or $\vec{a}$ direction), [010] and [012] (or $\vec{b}$ direction), and [001] (or $\vec{c}$ direction). Indexed crystal facets are shown in Figure S11 of the SI. Growth rates were measured at a fixed flow rate $\left(24 \mathrm{~mL} \mathrm{~h}^{-1}\right)$ of solution ( $\mathrm{pH} \mathrm{8.6)} \mathrm{with} \mathrm{a} \mathrm{composition} \mathrm{of} 2.5 \mathrm{mM}$ $\mathrm{MgCl}_{2} \cdot \mathrm{H}_{2} \mathrm{O}: 2.5 \mathrm{mM} \mathrm{NH}_{4} \mathrm{H}_{2} \mathrm{PO}_{4}: x \mu \mathrm{g} \mathrm{mL} \mathrm{mL}^{-1}$ inhibitor $(x=20$ for TMP, PP, and TP; $x=1$ for HMP, PA, and P45). Error bars equal one standard deviation obtained from measurements of 30 or more crystals in a single batch. (B and C) Optical micrographs extracted from Movie S2 at times 0 and 35 min showing the same struvite crystal in the absence (B) and presence $(\mathrm{C})$ of $1 \mu \mathrm{g} \mathrm{mL} \mathrm{m}^{-1} \mathrm{PA}$. Scale bars equal $10 \mu \mathrm{m}$.

nucleation theory, the free energy of the system is governed by the solution supersaturation and the free energy of the step edge $^{51-54}$. At the conditions used for in situ AFM, the concentration of HMP is too small to lower supersaturation via its sequestration of free $\mathrm{Mg}^{2+}$ ions (i.e. $\mathrm{Mg}^{2+}$ : $\mathrm{HMP}>500$ in growth media). This suggests adsorbed HMP on struvite surfaces may alter the step edge energy; however, it is also possible that HMP alters the kinetics of layer advancement owing to specific interactions with growth sites. Traditionally the mechanism of inhibition is identified by monitoring changes in step velocity as a function of inhibitor concentration where the resulting shape of the velocity profile indicates either kink blocking or step pinning ${ }^{55-57}$. The dramatic changes in struvite surface topography (Figure 6A-D) make it difficult to track step velocity and identify the mechanism of HMP inhibition; 
although, the presence of corrugated steps is consistent with step pinning.

Prolonged exposure of struvite surfaces to growth media containing HMP leads to roughening and the disappearance of visible layers (Figure 6D). Measurement of the root-mean squared (RMS) roughness for a fixed surface area during continuous scanning yields values of $0.43 \mathrm{~nm}$ for layered surfaces (Figure 7A) and $1.57 \mathrm{~nm}$ for rough interfaces exposed to HMP (Figure 7B). The rough features correspond to protrusions with step heights ranging from 0.5 to $7 \mathrm{~nm}$, which are much larger than those of single steps (Figure 7C). The topography of crystal surfaces exposed to equivalent concentrations of P45 and PA also show similar

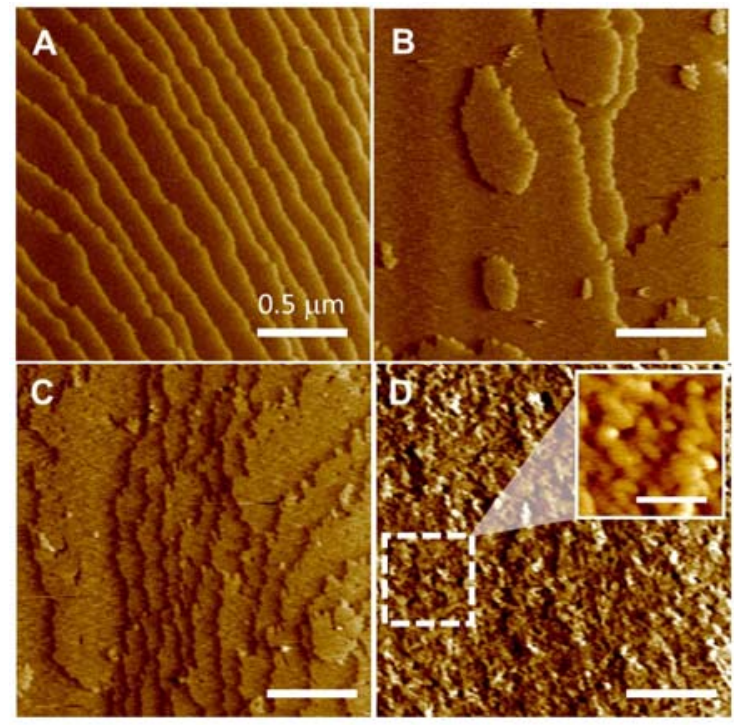

Figure 6. Time-resolved in situ AFM deflection mode images at a fixed scan area of a struvite (101) surface. Images are extracted from Movie S3 during growth in a solution containing $2.5 \mathrm{mM} \mathrm{MgCl}_{2} \cdot \mathrm{H}_{2} \mathrm{O}: 2.5 \mathrm{mM}$ $\mathrm{NH}_{4} \mathrm{H}_{2} \mathrm{PO}_{4}: 0.3 \mu \mathrm{g} \mathrm{mL}{ }^{-1} \mathrm{HMP}$. (A) First image of the struvite surface with evenly spaced steps that propagate across the surface. This image was obtained immediately after introducing HMP (time $t=0 \mathrm{~min}$ ) following an initial period of growth in the same solution without inhibitor. (B) Image at $\mathrm{t}=10 \mathrm{~min}$ showing wider terraces (i.e., reduced step density) and 2-dimensional islands. (C) Image at $t=17$ min showing a higher density of steps with corrugated edges. (D) Image at $t=32$ min showing a roughened surface where distinct layers are no longer discernible. Inset: higher magnification image of the region within the dashed box showing nanoparticle protrusions $($ scale bar $=100 \mathrm{~nm}$ ).

characteristics wherein the layers are indiscernible owing to a high coverage of surface protrusions (Figure S12A and B, respectively). The exact origin of surface roughness is unknown. Dynamic light scattering (DLS) of growth solutions show no trace of particulates, which does not exclude the possibility that particles exist in low concentrations that fall below the detection limit of DLS. In situ chemical force microscopy (CFM) measurements were performed according to a previous study ${ }^{58}$ using growth solutions with and without HMP to record approach and retraction curves of an AFM silicon nitride tip impinged upon control (pristine) and rough crystal surfaces, respectively. CFM tip deflection profiles of the former (Figure 7D) exhibit a typical curve for hard surfaces where an attractive tip-crystal interaction yields an adhesion (or unbinding) force of $2.3 \pm 0.5 \mathrm{nN}$. Conversely, the profile of the surface exposed to HMP is characteristic of materials lacking strong tip-surface interactions. Likewise, the profile for rough surfaces resembles those reported for soft materials, such as polymers ${ }^{59}$, whereas CFM profiles for even softer gel-like surfaces exhibit two signature features that are absent in Figure 7D: a nonlinear approach curve (yield stress) with hysteresis upon retraction ${ }^{58}$.

Ex situ X-ray photon spectroscopy (XPS) measurements of rough surfaces extracted from growth solutions reveal peaks of $\mathrm{Mg}$ and $\mathrm{P}$ with no apparent difference in composition $(\mathrm{Mg} / \mathrm{P} \approx 1)$ relative to control crystals with layered crystalline surfaces; thus, the exact structure of rough protrusions is difficult to establish. Kato et al. ${ }^{60}$ showed similar rough features on hydroxyapatite, $\mathrm{Ca}_{5}\left(\mathrm{PO}_{4}\right)_{3}(\mathrm{OH})$, plates treated with PolyP solutions and suggested these features may be surface-adsorbed PolyPs bound with $\mathrm{Ca}^{2+}$ ions. Moreover, it is interesting to point out that previous studies have demonstrated the presence of particles in
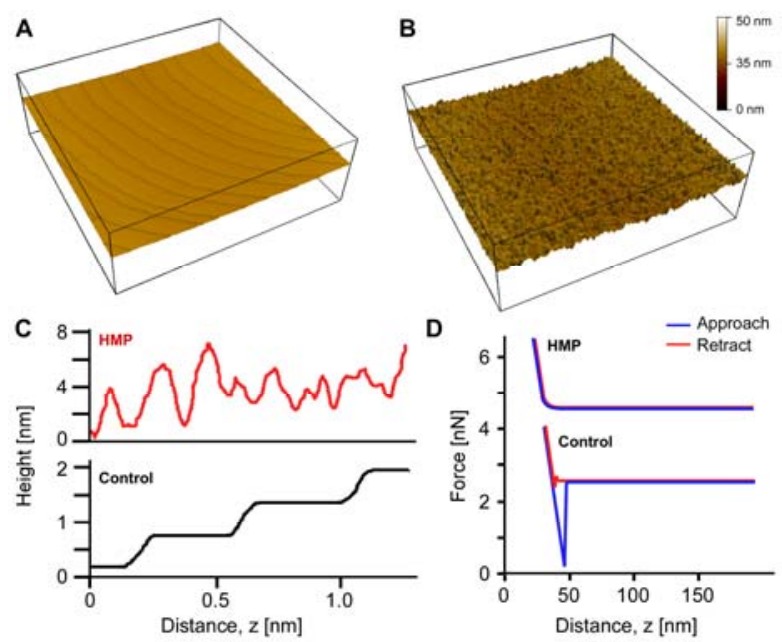

Figure 7. Effect of HMP on struvite surface topography. Three-dimensional height-mode images of struvite surfaces exposed to growth solutions (A) without inhibitor (control) and (B) with $3 \mu \mathrm{g} \mathrm{mL}^{-1} \mathrm{HMP}$. (C) Representative height profiles of surfaces in panels A and B showing vicinal and rough surfaces, respectively. (D) CFM approach (blue) and retraction (red) curves as a function of distance $\mathrm{z}$ from substrates for the control (bottom) and HMP-exposed (top) samples.

solutions comprised of PolyPs and cationic species (e.g. $\mathrm{Mg}^{2+}$ ions). Similar types of particulates containing PolyPs and inorganic divalent cations have also been observed in nature, such as granules in mitochondria, while synthetic analogues can be prepared in alkaline solutions with excess cations ${ }^{61-}$ ${ }^{64}$ for use in applications of bone regeneration ${ }^{65}$ and cartilage repair $^{64}$, among others.

CFM measurements are highly suggestive that roughened interfaces have a different structure than a pristine crystal surface. More definitive proof that these layers are a soft material is derived from AFM images in contact mode (harder engage) where areas under continuous scanning (or rastering) of the AFM tip are markedly different than those of surrounding (non-imaged) regions. Indeed, enlarged scanning areas of a rough struvite (101) surface after a period of in situ imaging shows a notable difference between the scanned and surrounding regions (Figure 8A). Continuous imaging of a fixed area of a crystal substrate with periodic enlargements of the scanning area reveal a monotonic increase in the height of the imaged region (Figure 8B); thus, continued growth occurs in areas of tip rastering while growth in regions unperturbed by the 
movement of the tip is suppressed. Confirmation of fully inhibited growth in non-imaged regions is difficult to extract from AFM owing to the lack of a reference point (i.e. constant baseline); however, microfluidics experiments under identical conditions confirmed that struvite growth is completely suppressed. Thus, we posit that the AFM tip temporarily disrupts or removes rough features to allow growth in the [101] direction, normal to the plane of imaging, which is reflected by the temporal increase in the height profile (Figure 8B). While the exact structure of the rough features cannot be discerned from these measurements, we hypothesize they are amorphous in nature, which is qualitatively consistent with their facile removal as a result of AFM tip rastering, unlike layered crystal surfaces (control) that are unaffected by imaging with harder engage. Moreover, the observation that rough features fully suppress struvite surface growth is another indication that their structure is distinct relative to the underlying crystal lattice.
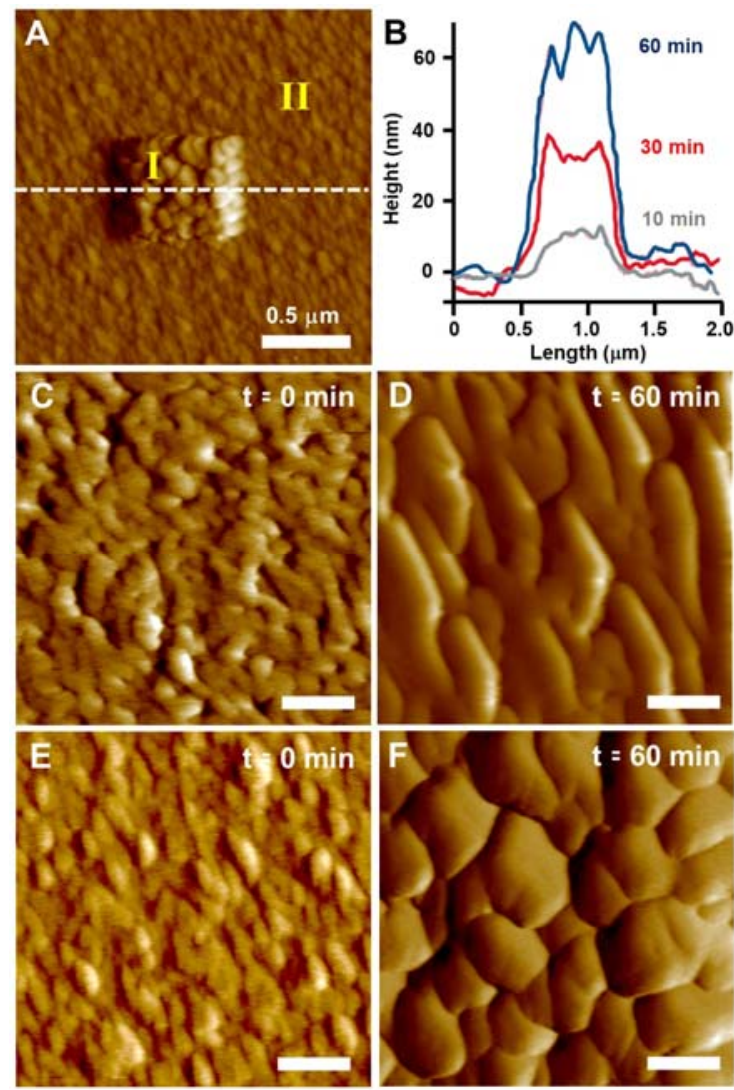

Figure 8. Three-dimensional growth of rough interfaces. (A) AFM deflection mode image of an enlarged scan area of a crystal surface during in situ measurements in a solution containing $3 \mu \mathrm{g} \mathrm{mL}^{-1} \mathrm{HMP}$ showing (I) an imaged area after 30 min of continuous scanning in contact mode and (II) the surrounding (non-scanned) region. (B) Time-resolved height profiles across the dashed line in image A. (C-F) Images showing the evolution of rough protrusions at times 0 and 60 min during continuous imaging in contact mode in the presence of $(C$ and $D) 0.3 \mu \mathrm{g} \mathrm{mL}^{-1}$ and $(\mathrm{E}$ and F) $3 \mu \mathrm{g} \mathrm{mL} \mathrm{m}^{-1}$ of HMP. Scale bars equal $100 \mathrm{~nm}$ unless otherwise noted.

Interestingly, the regions where growth occurs in the presence of HMP as a result of AFM tip movement reveal changes in both the size and morphology of rough features (Figure 8C-F). This phenomenon was observed over a broad range of HMP concentrations $\left(0.3-3 \mu \mathrm{g} \mathrm{mL}^{-1}\right)$. The rough protrusions are initially globular in shape (Figure $8 \mathrm{C}$ and E), but after 60 min of imaging the average size of protrusions increases (Figure 8D and F). Time-resolved AFM images also indicate changes in feature shape, such as the anisotropic morphology observed at lower HMP concentration where features seemingly align in the [012] direction (Figure 8D). In surrounding regions not under continuous scanning, there is no apparent change in surface topography (Figure S13), which is consistent with microfluidics showing fully arrested growth in all crystallographic directions. At concentrations below $0.3 \mu \mathrm{g}$ $\mathrm{mL}^{-1} \mathrm{HMP}$, we do not observe roughened interfaces and struvite surface growth is inhibited through a classical route involving HMP-crystal interactions. Indeed, AFM measurements of (101) step advancement in growth solutions containing $0.25 \mu \mathrm{g} \mathrm{mL}{ }^{-1} \mathrm{HMP}$ result in step corrugation and reduced step velocity (Figure S14), suggesting a critical level of HMP (around HMP/Mg $\sim 0.02 \%$ ) triggering the onset of surface roughness and growth succession. AFM studies with moderately-effective inhibitors (PP, TMP, and TP) at concentrations as high as $10 \mu \mathrm{g} \mathrm{mL}^{-1}$ do not result in surface roughening (Figure S15). For modifiers that induce surface roughening (i.e. HMP, P45, and PA), we observe that layered growth of struvite surfaces is recovered by exposing crystals with roughened interfaces to fresh growth solutions in the absence of inhibitor (see Figure S16). Thus, inhibition by this unique mechanism is a reversible phenomenon.

\section{CONCLUSION}

In summary, we evaluated six commercially available PolyPs as potential inhibitors of struvite scale formation. Bulk crystallization assays were performed under two different operating conditions. Stirring was used to assess the extent of crystallization where the compounds tested were classified into three categories based on their efficacy as crystallization inhibitors: ineffective (i.e. PP, TMP, and TP), moderately effective (i.e. HMP and P45), and highly effective (i.e. PA). Similar studies were performed under quiescent conditions in which it was observed that the efficacy of HMP and P45 was similar to that of PA. Under these conditions, all three PolyPs fully suppress struvite nucleation. Among these potent inhibitors, PA facilitates the precipitation of amorphous solids while the other two inhibitors stabilize highly supersaturated solutions.

On the basis of these observations, systematic in situ measurements were conducted using highly effective inhibitors that did not promote precipitation. The efficacy of HMP and P45 did not diminish in microfluidics studies, indicating that low flow rates do not impede their effect, as was observed under more severe conditions of stirring. Indeed, time-resolved measurements of struvite crystal growth by microfluidics revealed that all three potent inhibitors of nucleation also act as efficient inhibitors of crystal growth. An interesting observation when comparing the list of PolyPs examined in this study (Figure 1A) is the impact of structure and size of the inhibitor. For example, three phosphates arranged in a linear chain (TP) are slightly more effective than their arrangement in a ring (TMP); however, when the size of the ring is increased from 3 to 6 phosphates (HMP) the efficacy is dramatically enhanced. Moreover, when comparing HMP to another ring bearing 6 phosphates (PA), but with a carbon backbone, the efficacy of the latter is more robust over all of the conditions tested (i.e. quiescent, stirred, and flow). These findings highlight a ubiquitous observation among numerous crystal growth inhibitors, which is that subtle variations in molecule 
structure and composition can lead to marked differences in their efficacy.

The mechanism by which HMP, P45, and PA inhibit struvite surface growth via the generation of a roughened interface is unique, but not well understood. Although the composition of the layer is comprised of stoichiometric magnesium and phosphorus, the physical properties of the layer are distinctly different from those of crystalline struvite. The absence of a tip-substrate pull-off profile in CFM measurements and the ability of the tip to perturb the roughened layer during in situ AFM imaging are two aspects not observed during similar measurements on layered (or pristine) struvite crystal surfaces. We hypothesize that the layers may be comprised of disordered (or amorphous) material facilitated by interactions with PolyPs; however, the exact composition and structure of the roughened features remains elusive. Irrespective of their physicochemical properties, the roughened interface is highly effective in suppressing struvite crystal growth. One unique aspect of PolyPs is their affinity to suppress the growth of all principal crystallographic surfaces: [101] (or $\vec{a}$ direction), [010] and [012] (or $\vec{b}$ direction), and [001] (or $\vec{c}$ direction). This enables PolyPs to completely suppress crystallization in all directions at relatively low concentrations. To our knowledge, few growth inhibitors reported in literature exhibit such broad affinity for crystal surfaces. It is far more common to observe an inhibitor that targets one or two surfaces, leading to inhibition of bulk crystal growth in the range of $60-80 \%$. Macromolecules tend to be more effective and can inhibit crystal growth in the $80-100 \%$ range; however, it is rare to observe modifiers with an efficiency leading to full suppression.

It is also uncommon to observe (macro)molecules capable of fully suppressing crystal nucleation. The exact mechanism by which HMP, P45, and PA achieve this is a subject of ongoing investigation. A more frequent observation in literature is an inhibitors ability to perturb the rate of nucleation, leading to fewer, albeit larger, crystals. These cases typically involve the use of high inhibitor concentration. For the PolyPs examined in this study, HMP and P45 yield only a few observable crystals in bulk assays at low inhibitor concentration. Under conditions of stirring, HMP and P45 are less effective nucleation inhibitors in comparison to PA, which fully inhibits nucleation under all conditions tested in this study. The stochastic nature of nucleation, in accordance with classical nucleation theory, would seemingly imply that this process is unlikely to be fully suppressed. Exceptions would apply to inhibitors that function as sequestering agents capable of removing ions (e.g. free $\mathrm{Mg}^{2+}$ ) from solution, thus lowering supersaturation to levels that fall within the limit of metastability where nucleation is prevented. In this study, the amount of PolyP required to inhibit nucleation is orders of magnitude smaller than the solute; therefore, sequestration is not a factor contributing to the observed effect. Another possible explanation may be a deviation from classical nucleation owing to the formation of pre-nucleation clusters wherein inhibitor-cluster interactions may be responsible for the full suppression of nucleation. To our knowledge, this nonclassical pathway has not been confirmed and remains a subject for future investigation.

Despite their unknown mechanism(s) of action, our discovery of the dual modes by which PolyPs inhibit both nucleation and crystal growth reveal a level of efficiency for modifiers of struvite that is rarely observed across a broad range of inorganic and organic crystallization. Indeed, in situ formation of amorphous surface coating is a unique mechanism that deviates from the classical inhibitory mechanism and facilitates complete suppression of layered growth. This holds a potentially broader applicability to other minerals that involve various cationic species in the formation environment.

\section{EXPERIMENTAL SECTION}

Materials. The following reagents were purchased from Sigma Aldrich (St. Louis, MO, USA): magnesium chloride hexahydrate (BioXtra, $\geq 99.0 \%$ ), ammonium dihydrogen phosphate $(99.999 \%$ trace metals basis), sodium hydroxide $(\geq 98.0 \%$ ), trisodium trimetaphosphate $(\geq 95 \%)$, sodium triphosphate pentabasic ( $\geq 98 \%$ ), sodium pyrophosphate tetrabasic ( $\geq 95 \%)$, sodium hexametaphosphate $(96 \%)$, sodium phosphate glass (type 45), sodium chloride (BioXtra, $\geq$ $99.5 \%$ ), and sodium hydroxide solution $(1.0 \mathrm{~N})$. Phytic acid dipotassium salt was purchased from Boc Sciences. Filter papers were purchased from Whatman. Deionized water used in all experiments was purified with an Aqua Solutions RODI water purification system $(18.2 \mathrm{M} \Omega)$. All reagents were used as received without further purification.

Bulk Crystallization. Batch crystallization was performed by adding stock solutions into a $20-\mathrm{mL}$ glass vial in the following order: DI water, $\mathrm{NaCl}_{(\mathrm{aq})}$, and aliquots of $50 \mathrm{mM}$ $\mathrm{NH}_{4} \mathrm{H}_{2} \mathrm{PO}_{4,(\mathrm{aq})}, 50 \mathrm{mM} \mathrm{MgCl}_{2} \cdot 6 \mathrm{H}_{2} \mathrm{O}_{(\mathrm{aq})}$, and $1000 \mu \mathrm{g} \mathrm{mL}{ }^{-1}$ inhibitor solutions. The final growth solutions with a total volume of $10 \mathrm{~mL}$ had a composition of $7 \mathrm{mM} \mathrm{MgCl}_{2} 6 \mathrm{H}_{2} \mathrm{O}: 7 \mathrm{mM}$ $\mathrm{NH}_{4} \mathrm{H}_{2} \mathrm{PO}_{4}: 150 \mathrm{mM} \mathrm{NaCl}: x \mu \mathrm{g} \mathrm{mL}^{-1}$ inhibitor, and the $\mathrm{pH}$ of the growth solution was adjusted to $\mathrm{pH} 8.6$ by the addition of appropriate volumes of $1 \mathrm{M} \mathrm{NaOH}$ solution. The sample vials were first stirred for 15 minutes at $1200 \mathrm{rpm}$ using a magnetic stir bar and were then left undisturbed at $22( \pm 1)^{\circ} \mathrm{C}$ for $72 \mathrm{~h}$. The final crystals were observed in the solution by optical microscopy using a Leica DMi8 instrument. Crystals were than collected by vacuum filtration and dried in air overnight before further analysis. Crystals were analyzed with a Siemens D5000 X-ray diffractometer (XRD) using a $\mathrm{CuK} \alpha$ source (40 $\mathrm{kV}, 30 \mathrm{~mA}$ ) and were confirmed using struvite XRD reference patterns provided by the database of the RRUFF project with ID: R050540.1. Ex situ microscopy measurements were obtained by using FEI 235 dual-beam focused ion beam scanning electron microscopy (SEM). SEM samples were coated with 15-20 nm gold to reduce electron beam charging.

Kinetic measurements of struvite formation were performed by tracking the $\mathrm{pH}$ of the bulk crystallization solution under constant stirring at $600 \mathrm{rpm}$. The $\mathrm{pH}$ of growth solutions was measured at $30 \mathrm{sec}$ intervals using an Orion 3-Star Plus $\mathrm{pH}$ benchtop meter equipped with a ROSS Ultra electrode (8102BNUWP).

In situ Characterization of Growth. A microfluidics device was used to examine struvite growth at macroscopic length scale. The device (poly-di-methyl-siloxane (PDMS) on glass) used for these experiments followed the same set up and fabrication protocol as reported in previous work ${ }^{50,66}$. This system was monitored under continuous supply of a growth solution using a semi-automatic inverted light microscope (Leica DMi8 equipped with PL Fluotar 5x, 10x, 20x, and N Plan L 50x objectives).

Struvite seed crystals were prepared in a $20 \mathrm{~mL}$ vial containing a solution of composition $7 \mathrm{mM} \mathrm{MgCl} 26 \mathrm{H}_{2} \mathrm{O}: 7 \mathrm{mM}$ $\mathrm{NH}_{4} \mathrm{H}_{2} \mathrm{PO}_{4}: 150 \mathrm{mM} \mathrm{NaCl}(\mathrm{pH} 8.5)$. The order of reagent addition was identical to the procedure described above, using continuous stirring $(600 \mathrm{rpm})$. The solution was mixed with a stir bar for a short time (ca. $30 \mathrm{sec}$ ) to minimize nucleation, 
followed by its immediate transfer (by syringe) to the growth chamber of the microfluidics device.

Growth solutions for microfluidics studies containing $x$ $\mu \mathrm{g} \mathrm{mL}^{-1}$ inhibitor were prepared with molar concentrations of $2.5 \mathrm{mM} \mathrm{MgCl}_{2} \cdot 6 \mathrm{H}_{2} \mathrm{O}: 2.5 \mathrm{mM} \mathrm{NH}_{4} \mathrm{H}_{2} \mathrm{PO}_{4}$. An appropriate volume of $1 \mathrm{M} \mathrm{NaOH}$ was added to adjust solution $\mathrm{pH}$ to 8.6. The growth solution was delivered to the microchannel at flow rates of $24 \mathrm{~mL} \mathrm{~h}^{-1}$ using a dual syringe pump (Chemyx, Fusion 4000 ) and two syringes (plastic BD syringe, $30 \mathrm{~mL}$ ) with an in-line mixing configuration. Solution 1 contained magnesium chloride mixed with ammonium dihydrogen phosphate, and Solution 2 contained sodium hydroxide and inhibitor. Combinations of the two solutions resulted in a final concentration of $2.5 \mathrm{mM}$ of each component, the desired inhibitor concentration and a $\mathrm{pH}$ of 8.6 after exiting a mixing chamber placed prior to the entrance of the growth chamber. For in situ time-resolved studies, images were acquired every $5 \mathrm{~min}$ at multiple positions along the microfluidics channel. Optical micrographs of crystals were analyzed using Image $(\mathrm{NIH})$ for the average length along the $\vec{a}, \vec{b}$, and $\vec{c}$ directions. The growth rate was measured by linear regression of crystal length versus time data. The efficacy of struvite growth inhibitors was quantitatively assessed through calculation of the percent inhibition, defined as:

$$
\mathrm{x}=\left(1-\frac{r_{\text {inhibitor }}}{r_{\text {control }}}\right) \times 100 \%
$$

where $r_{\text {control }}$ and $r_{\text {inhibitor }}$ are the growth rates in the absence and presence of inhibitor, respectively.

In situ atomic force microscopy (AFM) was performed to examine the temporal changes in topographical features on struvite crystal surfaces. Struvite crystals were prepared by directly placing an AFM specimen disk (Ted Pella) into a bulk crystallization vial overnight. The sample was removed from the vial and dried in air immediately before use. All AFM measurements were performed in a Cypher ES instrument (Asylum Research, Santa Barbara, CA) using silicon nitride probes with gold reflex coating and a spring constant of 0.15 $\mathrm{N} / \mathrm{m}$ (Olympus, TR800PSA). The liquid cell (ES-CELLGAS) contained two ports for inlet and outlet flow to maintain constant supersaturation during AFM measurements. Solutions used for AFM experiments were the same as the solutions used for the microfluidics experiments. The growth solution was delivered to the liquid cell using an in-line mixing configuration where the two solute solutions were combined immediately before being introduced into the cell (similar to the microfluidics configuration). Combinations of the two solutions resulted in a final concentration of $2.5 \mathrm{mM}$ of each component, the desired inhibitor concentration and a $\mathrm{pH}$ of 8.6 after exiting a mixing chamber placed prior to the entrance of the AFM liquid cell. Freshly prepared growth solutions were used for each experiment (within one hour of their preparation). Continuous imaging was performed at ambient temperature in contact mode with a scan rate of $0.5-10 \mathrm{~Hz}$ at 256 lines per scan.

Chemical Force Microscopy We used the Cypher ES instrument to measure the unbinding force between an AFM tip and struvite crystal surfaces. All measurements were carried out using non-functionalized silicon nitride probes with gold reflective coating and a spring constant of $0.08 \mathrm{~N} \mathrm{~m}^{-1}$ (Olympus, PNP-TR). The cantilever was calibrated in air to verify the spring constant using an algorithm provided by the vendor. Force measurements were performed on struvite surfaces in the absence and presence of inhibitors (HMP, P45, and PA) under identical conditions as in situ AFM growth experiments. We first imaged struvite crystal surfaces in contact mode to locate regions for CFM measurements. We selected a tip speed of $1.98 \mu \mathrm{m} \mathrm{s}^{-1}$ and trigger points of $1.00 \mathrm{~V}$. Surface areas of $2 \times 2 \mu \mathrm{m}^{2}$ were analyzed to gather more than 50 data points for statistical analysis.

\section{ASSOCIATED CONTENT}

\section{SUPPORTING INFORMATION}

This material is available free of charge via the Internet at http://pubs.acs.org.

Details of phosphoric acid speciation, microfluidics device scheme, struvite crystal facet indexing, additional images (optical, and scanning electron micrographs), powder XRD patterns of precipitates formed in the presence and absence of polyphosphates, additional time-resolved images (optical micrographs and AFM) of struvite crystallization in solutions containing polyphosphates, movie captions, and additional references (PDF). Movies S1 - S3 show in situ microfluidics and AFM measurements of struvite growth under various conditions.

\section{AUTHOR INFORMATION}

\section{Corresponding Author}

*E-mail: jrimer@central.uh.edu

\section{Notes}

The authors declare no competing financial interests.

\section{Author Contributions}

All authors have given approval to the final version of the manuscript.

\section{ACKNOWLEDGMENTS}

We thank J.C. Conrad for help with the microfluidics design. J.D.R acknowledges financial support from The Welch Foundation (Award E-1794). N.J.I and C.P.M. acknowledge financial support from the Academy of Medical Sciences (AMS), the Wellcome Trust, the Government Department of Business, Energy and Industrial Strategy (BEIS), the British Heart Foundation and Diabetes UK [SBF004\1036], and the EPSRC-NIHR HTC Partnership IMPRESS Network [EP/N027345/1].

\section{REFERENCES}

(1) Li, H.; Yao, Q. Z.; Dong, Z. M.; Zhao, T. L.; Zhou, G. T.; Fu, S. Q. Controlled Synthesis of Struvite Nanowires in Synthetic Wastewater. ACS Sustain. Chem. Eng. 2019, 7 (2), 2035-2043.

(2) Hövelmann, J.; Putnis, C. V. In Situ Nanoscale Imaging of Struvite Formation during the Dissolution of Natural Brucite: Implications for Phosphorus Recovery from Wastewaters. Environ. Sci. Technol. 2016, 50 (23), 13032-13041.

(3) Loewenthal, R. E.; Kornmüller, U. R. C.; Van Heerden, E. P. Modelling Struvite Precipitation in Anaerobic Treatment Systems. Water Sci. Technol. 1994, 30 (12), 107.

(4) Kataki, S.; West, H.; Clarke, M.; Baruah, D. C. Phosphorus Recovery as Struvite: Recent Concerns for Use of Seed, Alternative Mg Source, Nitrogen Conservation and Fertilizer Potential. Resour. Conserv. Recycl. 2016, 107, 142-156.

(5) Hövelmann, J.; Stawski, T. M.; Freeman, H. M.; Besselink, R.; Mayanna, S.; Perez, J. P. H.; Hondow, N. S.; Benning, L. G. Struvite Crystallisation and the Effect of $\mathrm{Co}^{2+}$ Ions. Minerals 2019, 9 (9), 
503.

(6) Le Corre, K. S.; Valsami-Jones, E.; Hobbs, P.; Parsons, S. A. Phosphorus Recovery from Wastewater by Struvite Crystallization: A Review. Crit. Rev. Environ. Sci. Technol. 2009, 39 (6), 433-477.

(7) Yilmazel, Y. D.; Demirer, G. N. Nitrogen and Phosphorus Recovery from Anaerobic Co-Digestion Residues of Poultry Manure and Maize Silage via Struvite Precipitation. Waste Manag. Res. 2013, 31 (8), 792-804.

(8) Simoes, F.; Vale, P.; Stephenson, T.; Soares, A. The Role of PH on the Biological Struvite Production in Digested Sludge Dewatering Liquors. Sci. Rep. 2018, 8 (1), 1-9.

(9) Wang, J.; Burken, J. G.; Zhang, X.; Surampalli, R. Engineered Struvite Precipitation: Impacts of Component-Ion Molar Ratios and PH. J. Environ. Eng. 2005, 131 (10), 1433-1440.

(10) Doyle, J. D.; Parsons, S. A. Struvite Formation, Control and Recovery. Water Res. 2002, 36 (16), 3925-3940.

(11) Ueno, Y.; Fujii, M. Three Years Experience of Operating and Selling Recovered Struvite from Full-Scale Plant. Environ. Technol. 2001, 22 (11), 1373-1381.

(12) Griffith, D. P. Struvite Stones. Kidney Int. 1978, 13 (5), 372-382.

(13) Flannigan, R.; Choy, W. H.; Chew, B.; Lange, D. Renal Struvite Stones - Pathogenesis, Microbiology, and Management Strategies. Nat. Rev. Urol. 2014, 11 (6), 333-341.

(14) Large, T.; Krambeck, A. E. Management of Infection Stones. In The Role of Bacteria in Urology; Springer, 2019; pp 71-78.

(15) Hao, X. D.; Wang, C. C.; Lan, L.; Van Loosdrecht, M. C. M. Struvite Formation, Analytical Methods and Effects of $\mathrm{PH}$ and $\mathrm{Ca}$ 2+. Water Sci. Technol. 2008, 58 (8), 1687-1692

(16) Nelson, N. O; Mikkelsen, R. L.; Hesterberg, D. L. Struvite Precipitation in Anaerobic Swine Lagoon Liquid: Effect of PH and $\mathrm{Mg}: \mathrm{P}$ Ratio and Determination of Rate Constant. Bioresour. Technol. 2003, 89 (3), 229-236.

(17) Hesaraki, S.; Zamanian, A.; Moztarzadeh, F. Effect of Adding Sodium Hexametaphosphate Liquefier on Basic Properties of Calcium Phosphate Cements. J. Biomed. Mater. Res. - Part A 2009, 88 (2), 314-321.

(18) Andreola, F.; Castellini, E.; Manfredini, T.; Romagnoli, M. The Role of Sodium Hexametaphosphate in the Dissolution Process of Kaolinite and Kaolin. J. Eur. Ceram. Soc. 2004, 24 (7), 2113-2124.

(19) Elliot, M. N. Scale Control by Threshold Treatment. Desalination 1970, 8 (2), 221-236.

(20) Chung, J.; Sosa, R.; Rimer, J. D. Elucidating the Effects of Polyprotic Acid Speciation in Calcium Oxalate Crystallization. Cryst. Growth Des. 2017, 17 (8), 4280-4288.

(21) Farmanesh, S.; Ramamoorthy, S.; Chung, J.; Asplin, J. R.; Karande, P.; Rimer, J. D. Specificity of Growth Inhibitors and Their Cooperative Effects in Calcium Oxalate Monohydrate Crystallization. J. Am. Chem. Soc. 2014, 136 (1), 367-376.

(22) De Yoreo, J. J.; Qiu, S. R.; Hoyer, J. R. Molecular Modulation of Calcium Oxalate Crystallization. Am. J. Physiol. Physiol. 2006, 291 (6), F1123-F1132.

(23) Betty Hoac, Tina Kiffer-Moreira, Jose Luis Millan, M. D. M. Polyphosphates Inhibit Extracellular Matrix Mineralization in MC3T3-E1 Osteoblast Cultures. Bone 2013, 53 (2), 478-486.

(24) Robinson, T. E.; Hughes, E. A. B.; Wiseman, O. J.; Stapley, S. A.; Cox, S. C.; Grover, L. M. Hexametaphosphate as a Potential Therapy for the Dissolution and Prevention of Kidney Stones. J. Mater. Chem. B 2020, 8 (24), 10-15.

(25) Wang, L.; Zhang, W.; Qiu, S. R.; Zachowicz, W. J.; Guan, X.; Tang, R.; Hoyer, J. R.; Yoreo, J. J. D.; Nancollas, G. H. Inhibition of Calcium Oxalate Monohydrate Crystallization by the Combination of Citrate and Osteopontin. J. Cryst. Growth 2006, 291 (1), 160165.

(26) Grohe, B.; O’Young, J.; Ionescu, D. A.; Lajoie, G.; Rogers, K. A.; Karttunen, M.; Goldberg, H. A.; Hunter, G. K. Control of Calcium Oxalate Crystal Growth by Face-Specific Adsorption of an Osteopontin Phosphopeptide. J. Am. Chem. Soc. 2007, 129 (48), 14946-14951.

(27) Grases, F.; Perelló, J.; Isern, B.; Costa-Bauzá, A. Myo-Inositol
Hexakisphosphate (Phytate) Inhibits Calcium Carbonate Crystallisation in Hard Water. Water SA 2007, 33 (5), 749-754.

(28) Wesson, J. A.; Johnson, R. J.; Mazzali, M.; Beshensky, A. M. Stietz, S.; Giachelli, C.; Liaw, L.; Alpers, C. E.; Couser, W. G.; Kleinman, J. G. Osteopontin Is a Critical Inhibitor of Calcium Oxalate Crystal Formation and Retention in Renal Tubules. J. Am. Soc. Nephrol. 2003, 14 (1), 139-147.

(29) Qiu, S. R.; Wierzbicki, A.; Orme, C. A.; Cody, A. M.; Hoyer, J. R.; Nancollas, G. H.; Zepeda, S.; De Yoreo, J. J. Molecular Modulation of Calcium Oxalate Crystallization by Osteopontin and Citrate. Proc. Natl. Acad. Sci. 2004, 101 (7), 1811-1815.

(30) Grohe, B.; O’Young, J.; Ionescu, D. A.; Lajoie, G.; Rogers, K. A.; Karttunen, M.; Goldberg, H. A.; Hunter, G. K. Control of Calcium Oxalate Crystal Growth by Face-Specific Adsorption of an Osteopontin Phosphopeptide. J. Am. Chem. Soc. 2007, 129 (48), 14946-14951.

(31) O'Young, J.; Chirico, S.; Al Tarhuni, N.; Grohe, B.; Karttunen, M.; Goldberg, H. A.; Hunter, G. K. Phosphorylation of Osteopontin Peptides Mediates Adsorption to and Incorporation into Calcium Oxalate Crystals. Cells Tissues Organs 2008, 189 (1-4), 51-55.

(32) Hug, S.; Grohe, B.; Jalkanen, J.; Chan, B.; Galarreta, B.; Vincent, K.; Lagugné-Labarthet, F.; Lajoie, G.; Goldberg, H. A.; Karttunen, M.; Hunter, G. K. Mechanism of Inhibition of Calcium Oxalate Crystal Growth by an Osteopontin Phosphopeptide. Soft Matter 2012, 8 (4), 1226-1233.

(33) Hunter, G. K.; Grohe, B.; Jeffrey, S.; O’Young, J.; Sørensen, E. S.; Goldberg, H. A. Role of Phosphate Groups in Inhibition of Calcium Oxalate Crystal Growth by Osteopontin. Cells Tissues Organs 2008, $189(1-4), 44-50$.

(34) Grases, F.; Costa-Bauzá, A. Phytate (IP6) Is a Powerful Agent for Preventing Calcifications in Biological Fluids: Usefulness in Renal Lithiasis Treatment. Anticancer Res. 1999, 19 (5 A), 3717-3722.

(35) Thomson, R. T. Some Properties of Sodium Hexametaphosphate. Analyst 1936, 61 (722), 320-323.

(36) Eisenstein, N.; Williams, R.; Cox, S.; Stapley, S.; Grover, L. Enzymatically Regulated Demineralisation of Pathological Bone Using Sodium Hexametaphosphate. J. Mater. Chem. B 2016, 4 (21), 3815-3822.

(37) Termine, J. D.; Peckauskas, R. A.; Posner, A. S. Calcium Phosphate Formation in Vitro. II. Effects of Environment on AmorphousCrystalline Transformation. Arch. Biochem. Biophys. 1970, 140 (2), 318-325.

(38) Robertson, W. G. Factors Affecting the Precipitation of Calcium Phosphate in Vitro. Calcif. Tissue Res. 1973, 11 (4), 311-322.

(39) Tolba, E.; Müller, W. E. G.; Abd El-Hady, B. M.; Neufurth, M.; Wurm, F.; Wang, S.; Schröder, H. C.; Wang, X. High Biocompatibility and Improved Osteogenic Potential of Amorphous Calcium Carbonate/Vaterite. J. Mater. Chem. B 2016, 4 (3), 376386.

(40) Fleisch, H. Inhibitors and Promoters of Stone Formation. Kidney Int. 1978, 13 (5), 361-371.

(41) McLean, R. J. C.; Downey, J.; Clapham, L.; Wilson, J. W. L.; Nickel, J. C. Pyrophosphate Inhibition of Proteus Mirabilis-Induced Struvite Crystallization in Vitro. Clin. Chim. Acta 1991, 200 (2-3), 107-117.

(42) Olszynski, M.; Prywer, J.; Mielniczek-Brzóska, E. Inhibition of Struvite Crystallization by Tetrasodium Pyrophosphate in Artificial Urine: Chemical and Physical Aspects of Nucleation and Growth Cryst. Growth Des. 2016, 16 (6), 3519-3529.

(43) Kofina, A. N.; Demadis, K. D.; Koutsoukos, P. G. The Effect of Citrate and Phosphocitrate on Struvite Spontaneous Precipitation. Cryst. Growth Des. 2007, 7 (12), 2705-2712.

(44) Chung, J.; Granja, I.; Taylor, M. G.; Mpourmpakis, G.; Asplin, J R.; Rimer, J. D. Molecular Modifiers Reveal a Mechanism of Pathological Crystal Growth Inhibition. Nature 2016, 536 (7617), 446-450.

(45) Olszynski, M.; Prywer, J.; Mielniczek-Brzóska, E. Inhibition of Struvite Crystallization by Tetrasodium Pyrophosphate in Artificial Urine: Chemical and Physical Aspects of Nucleation and Growth. Cryst. Growth Des. 2016, 16 (6), 3519-3529. 
(46) Prywer, J.; Mielniczek-Brzóska, E. Formation of Poorly Crystalline and Amorphous Precipitate, a Component of Infectious Urinary Stones: Role of Tetrasodium Pyrophosphate. Cryst. Growth Des. 2019, 19 (2), 1048-1056.

(47) Prywer, J.; Mielniczek-Brzoska, E. Effect of (-)-Epicatechin on Poorly Crystalline and Amorphous Precipitate. The Role of Green Tea Compound in the Formation of Infectious Urinary Stones. Cryst. Growth Des. 2019, 20 (1), 148-156.

(48) Kumar, M.; Luo, H.; Román-Leshkov, Y.; Rimer, J. D. SSZ-13 Crystallization by Particle Attachment and Deterministic Pathways to Crystal Size Control. J. Am. Chem. Soc. 2015, 137 (40), 1300713017.

(49) Hasson, D.; Shemer, H.; Sher, A. State of the Art of Friendly “ Green " Scale Control Inhibitors : A Review Article. 2011, 50 (12), 7601-7607.

(50) Kim, D.; Olympiou, C.; McCoy, C. P.; Irwin, N. J.; Rimer, J. D. Time-Resolved Dynamics of Struvite Crystallization: Insights from the Macroscopic to Molecular Scale. Chem. Eur. J. 2019, 26 (16), 3555-3563.

(51) Chernov, A. A. Modern Crystallograph III; Springer, 1984.

(52) Michely, T.; Krug, J.; Islands, M. Atoms: Patterns and Processes in Crystal Growth Far From Equilibrium. Springer 2004, 61, 313.

(53) Tang, R.; Darragh, M.; Orme, C. A.; Guan, X.; Hoyer, J. R.; Nancollas, G. H. Control of Biomineralization Dynamics by Interfacial Energies. Angew. Chemie Int. Ed. 2005, 44 (24), 36983702 .

(54) Li, M.; Zhang, J.; Wang, L.; Wang, B.; Putnis, C. V. Mechanisms of Modulation of Calcium Phosphate Pathological Mineralization by Mobile and Immobile Small-Molecule Inhibitors. J. Phys. Chem. B 2018, 122 (5), 1580-1587.

(55) Chung, J.; Granja, I.; Taylor, M. G.; Mpourmpakis, G.; Asplin, J. R.; Rimer, J. D. Molecular Modifiers Reveal a Mechanism of Pathological Crystal Growth Inhibition. Nature 2016, 536 (7617), 446-450.

(56) Olafson, K. N.; Nguyen, T. Q.; Rimer, J. D.; Vekilov, P. G. Antimalarials Inhibit Hematin Crystallization by Unique DrugSurface Site Interactions. Proc. Natl. Acad. Sci. U. S. A. 2017, 114 (29), 7531-7536.

(57) Ma, W.; Lutsko, J. F.; Rimer, J. D.; Vekilov, P. G. Antagonistic Cooperativity between Crystal Growth Modifiers. Nature 2020, 577 (7791), 497-501.

(58) Kumar, M.; Choudhary, M. K.; Rimer, J. D. Transient Modes of Zeolite Surface Growth from 3D Gel-like Islands to 2D Single Layers. Nat. Commun. 2018, 9 (1), 1-9.

(59) Variola, F. Atomic Force Microscopy in Biomaterials Surface Science. Phys. Chem. Chem. Phys. 2015, 17 (5), 2950-2959.

(60) Kato, K.; Morita, K.; Hirata, I.; Doi, K.; Kubo, T.; Kato, K.; Tsuga, $\mathrm{K}$. Enhancement of Calcification by Osteoblasts Cultured on Hydroxyapatite Surfaces with Adsorbed Inorganic Polyphosphate. Vitr. Cell. Dev. Biol. - Anim. 2018, 54 (6), 449-457.

(61) Muller, W. E. G.; Ackermann, M.; Neufurth, M.; Tolba, E.; Wang, S.; Feng, Q.; Schröder, H. C.; Wang, X. A Novel Biomimetic Approach to Repair Enamel Cracks/Carious Damages and to Reseal Dentinal Tubules by Amorphous Polyphosphate. Polymers (Basel). 2017, 9 (4), 120.

(62) Tolba, E.; Wang, X.; Ackermann, M.; Neufurth, M.; Muñoz-Espí, R.; Schröder, H. C.; Müller, W. E. G. In Situ Polyphosphate Nanoparticle Formation in Hybrid Poly(Vinyl Alcohol)/Karaya Gum Hydrogels: A Porous Scaffold Inducing Infiltration of Mesenchymal Stem Cells. Adv. Sci. 2019, 6 (2), 1-15.

(63) Wang, X.; Schröder, H. C.; Müller, W. E. G. Amorphous Polyphosphate, a Smart Bioinspired Nano-/Bio-Material for Bone and Cartilage Regeneration: Towards a New Paradigm in Tissue Engineering. J. Mater. Chem. B 2018, 6 (16), 2385-2412.

(64) Wang, X.; Ackermann, M.; Tolba, E.; Neufurth, M.; Wurm, F.; Feng, Q.; Wang, S.; Schröder, H. C.; Müller, W. E. Artificial Cartilage Bio-Matrix Formed of Hyaluronic Acid and $\mathrm{Mg}^{2+}$ Polyphosphate. Eur. Cell. Mater. 2016, 32, 271-283.

(65) Schröder, H. C.; Wang, X.; Müller, W. E. G. Amorphous Polyphosphate Nanoparticles: Application of the
Morphogenetically Active Inorganic Polymer for Personalized Tissue Regeneration. J. Phys. D. Appl. Phys. 2019, 52 (36), 363001.

(66) Sosa, R. D.; Geng, X.; Reynolds, M.; Rimer, J. D.; Conrad, J. C. A Microfluidic Approach for Probing Hydrodynamic Effects in Barite Scale Formation. Lab Chip 2019, 19 (9), 1534-1544. 
TABLE OF CONTENT (TOC) GRAPHIC

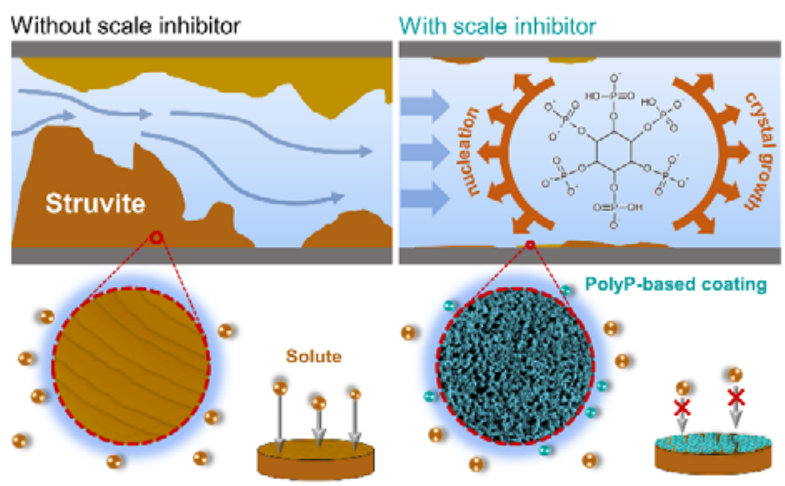

